\title{
Primary Survey
}

\section{Children with breathing difficulties}

Monica Lakhanpaul and collaborators, present a thoroughly researched and comprehensive guideline on the management of children who present with acute breathing difficulty. This is a very broad subject and the guideline itself (which spans some four charts covering acute breathing difficulty, stridor/stertor. Wheeze and cough) is large. As the authors point out, children with illness are a significant and increasing burden on Emergency Departments and breathing difficulty is a common presentation; these children are seen and assessed most frequently by relatively inexperienced doctors. This guideline, suitably modified for implementation locally, may help both the junior doctors and thereby the children. See page 850

\section{Chest pain again}

Despite cardiac sounding chest pain being one of the most common presenting conditions in western Emergency Departments and despite a great deal of published primary and secondary research, it is still difficult to undertake a rational clinical assessment. Steve Goodacre and colleagues report the findings of a secondary analysis of patients entered into the ESCAPE trial. (a trial looking at low-risk chest pain patientsall of whom had normal or non-diagnostic electrocardiograms). They looked at the clinical findings to see which, if any, were of any diagnostic value. Their findings are interesting and may, for some, be surprising. Emergency Physicians need to know why they do certain tasks and, having read this paper, it is worth reflecting on why we take histories at all in this patient group. See page 866

\section{Major incident triage}

Thierry Pelaccia and colleagues from Strasbourg report on a study looking at the performance of medical and nursing students performing disaster triage. In an interesting introduction they briefly discuss the range of triage systems in use across the world, broadly dividing them into those that use physiological measures and those that favour anatomical descriptors of injury. They postulate that both systems have their drawbacks and that a system encouraging "pattern recognition" may deliver better results. When you read the paper it is worth asking yourself whether there ever is a "right" answer in individual major incident triage, or whether, perhaps, it is the act of triage itself that is of benefit to the group of casualties as a whole. You can see what they found on page 902

\section{Accessibility of information}

Haleh Ayotollahi and colleagues have undertaken a qualitative study that explores the perspectives of Emergency Department staff concerning accessibility and confidentiality of the medical record. This is well worth a read-both to see what the staff interviewed thought and also to stimulate some thoughts of your own. What do we need to know about the history of our patients in the ED? To what degree does difficulty of access cause a clinical problem? How much potential loss of confidentiality will we (and our patients) accept? See page 857

\section{Children's fingers}

Injuries to the proximal interphalangeal joint are common in children, and many children who attend Emergency Departments with such injuries are $\mathrm{x}$-rayed.
Catherine Rimmer and Derek Burke, from Sheffield Children's Hospital, report the results of a 3 month observational study on children with these injuries. Are there any clinical features that help decide which injuries are significant and which are not? See page 854

\section{Pneumothorax size}

Clinical decisions about the management of spontaneous pneumothoraces are made after estimation of their size on chest $\mathrm{x}$ ray. In a fascinating study Dino Druda and Anne-Marie Kelly report on the variation in size estimation between inspiratory and expiratory films. Do you think your decisions would be altered depending on the respiratory phase of the $\mathrm{x}$-ray? See their results on page 861 to find out.

\section{Practice makes perfect, and lack} of practice ...

Competence is the current mantra in educational governance circles. Quite rightly Healthcare practitioners are not only meant to know how to do particular procedures but are expected, when they do undertake them, to perform them to a standard that is acceptable. Charles Deakin and colleagues, from an English Ambulance Service, report the results of a thought-provoking audit into the actual number times individual prehospital practitioners perform endotracheal intubation each year. They wonder whether the number they found (a median of 1 with a range of $0-11$ ) is sufficient to maintain competence. They point out that if competence is necessary then more practice time is needed. See page 891 